\title{
FFMCP: Feed-Forward Multi-Clustering Protocol Using Fuzzy Logic for Wireless Sensor Networks (WSNs)
}

\author{
Pankaj Kumar Mishra ${ }^{1, *}$ and Shashi Kant Verma ${ }^{2}$ \\ 1 Department of Computer Engineering, College of Technology, Uttarakhand 263145, India \\ 2 Department of Computer Engineering, G.B.P.E.C., Pauri Garhwal, Uttrakhand 263145, India; \\ skverma.gbpec@rediffmail.com \\ * Correspondence: pkmishra.cs@gmail.com
}

check for updates

Citation: Mishra, P.K.; Verma, S.K. FFMCP: Feed-Forward Multi-Clustering Protocol Using Fuzzy Logic for Wireless Sensor Networks (WSNs). Energies 2021, 14, 2866. https://doi.org/10.3390/ en14102866

Academic Editor: Gwanggil Jeon

Received: 5 April 2021

Accepted: 6 May 2021

Published: 16 May 2021

Publisher's Note: MDPI stays neutral with regard to jurisdictional claims in published maps and institutional affiliations.

Copyright: (c) 2021 by the authors. Licensee MDPI, Basel, Switzerland. This article is an open access article distributed under the terms and conditions of the Creative Commons Attribution (CC BY) license (https:/ / creativecommons.org/licenses/by/ $4.0 /)$.
Abstract: The restriction on the battery life of sensors is a bottleneck for wireless sensor networks (WSNs). This paper proposes a new feed-forward multi-clustering protocol (FFMCP) to boost the network lifetime. The utilization of fuzzy logic helps to overcome the uncertainties in the value of input parameters. The proposed protocol selects the most suitable cluster heads ( $\mathrm{CHs})$ using the multi-clustering method. A multi-clustering technique is defined utilizing the node's information of the previous round and a fuzzy inference system to decide the CHs. The sensor nodes spend energy due to non-uniform $\mathrm{CH}$ distribution and long-distance data transmission by member nodes. The main focus of the proposed protocol is to reduce the member node distance. Our proposal distributes $\mathrm{CH}$ nodes uniformly using unequal clustering. The simulation outcome reveals that the proposed algorithm(FFMCP) has better performance in terms of tenth node death (TND), half node death (HND), remaining energy after 800 rounds (E_800), and average energy spent per round (AVG_PR) as compared to standard clustering schemes in the past.

Keywords: multi-clustering protocol; wireless sensor network; fuzzy inference system; unequal clustering

\section{Introduction}

The definition of a wireless sensor network considers many cheap nodes with limited energy and processing capability to facilitate the sensing/collection of environmental parameters. The wireless sensor network helps in the formation of IoT infrastructure and is a crucial research area.

To preserve the sensor node's energy is the thrust part, as sensor nodes have a limited power supply. Nodes with a limited power supply will reduce the network performance; hence, designing a better routing algorithm is a challenge [1-3]. The different areas for better application of wireless network systems (WSNs) are environment monitoring [4,5], battle ground observation $[6,7]$, patient monitoring $[8,9]$, monitoring of manufacturing process [10], structural monitoring [11,12], building intelligent homes [13,14], vehicle supervision and recognition $[10,15]$, etc. Clustering performs a key role in maintaining energy efficiency and improving network lifetime [16-20]. Clustering enables an extraordinary node called the cluster head $(\mathrm{CH})$ to work as a leader node. The nodes joining the $\mathrm{CHs}$ to form clusters are cluster member $(\mathrm{CM})$ nodes. The $\mathrm{CH}$ performs the data gathering task from CMs and then forwards it to the base station (BS), the unlimited battery power node [21,22]. The way to perform $\mathrm{CH}$ selection ensures performance gain, saves the node's energy, and guarantees better communication and scalability in the network [23-28].

The multi-clustering protocol is successful because of proper input parameter selection in a particular round of algorithm execution. The contributions of the feed-forward multiclustering protocol (FFMCP) method are:

- Definition of two different combinations of input parameters for $\mathrm{CH}$ selection in a round of algorithm e;xecution. Each grouping of input parameters works separately for deciding CHs; 
- Network structure in a round act significant function in deciding the $\mathrm{CH}$ in the forthcoming round of the algorithm execution. Proper consideration of the input parameters, so that network information propagates forward and contributes to finalizing the $\mathrm{CHs}$;

- Carry out the analysis of the proposed protocol with notable clustering methods for WSNs.

\section{Related Works}

Clustering has been a fundamental research area in all kinds of networks, particularly for WSNs. Fuzzy logic adds extra benefits to perform clustering. This section expresses relevant protocols to perform clustering in WSNs.

The low-energy adaptive clustering hierarchy (LEACH) [29] method is the basic clustering technique using probability-based randomization for nodes. The nodes of different clusters calculate threshold value by applying the following equation:

$$
T(n)=\left\{\begin{array}{c}
\frac{p}{1-p\left(r \bmod \frac{1}{p}\right)} \text { if } n \in M \\
0, \text { otherwise }
\end{array}\right.
$$

where the letters $M, n, p, r$ represent the group of non-cluster head (member) nodes for the previous round, node's ID, the probability for $\mathrm{CH}$, and round number, respectively. $\mathrm{LEACH}$ completes the task of execution in two consecutive phases. Initial processing carries out in the cluster set-up phase, and then the steady-state phase executes. Threshold computations by nodes and comparison with randomly generated numbers occur in the cluster set-up phase. Lesser is the value of a randomly generated number in comparison to the threshold value, greater will be a chance for the node to employ as a $\mathrm{CH}$. Cluster formation takes place by considering the nearest $\mathrm{CH}$ node to form different groups. $\mathrm{CH}$ carry out data transmission via a single-hop method and lose more residual energy. Cluster head selection using simple probabilistic calculation is the advantage of the LEACH protocol.

Threshold sensitive energy efficient sensor network protocol (TEEN) [30] is a datacentric protocol using a probabilistic approach. It works hierarchically and transfers data only if a particular event occurs. It works reactively, especially for applications where time is critical. It is defined as homogeneous networks. Cluster head selection executes like LEACH protocol; additionally, TEEN introduces a hard and soft threshold to minimize the transmission. The hard threshold value permits less data transmission. The TEEN protocol is not suitable for periodic data gathering.

Fuzzy energy-aware unequal clustering algorithm (EAUCF) [31] execute clustering in a distributed manner by using a technique based on fuzzy logic. The decision for a proper cluster radius ensures better savings of the node's energy. Fuzzy logic uses nodes' remaining energy and distance from the base station to calculate the cluster radius. The initial phase of the algorithm calculates a set of tentative $\mathrm{CHs}$ using the probabilistic method. Generally, the threshold value changes in algorithm execution rounds, but it is unchanging for the EAUCF algorithm. The comparison of random numbers with threshold value decides the final $\mathrm{CHs}$ and completes the algorithm execution task. The lower energy tentative $\mathrm{CH}$ in the communication range of another higher energy tentative $\mathrm{CH}$ quits from the election.

Fuzzy logic based energy efficient clustering hierarchy (FLECH) [32] evaluates clusters assuming a non-uniform WSN scenario. The probable value for $\mathrm{CH}$ considers three input parameters. It performs calculations utilizing fuzzy concepts in Matlab. The major drawback is limited fuzzy output calculation. The algorithm executes in two phases to complete the task of clustering.

Distributed unequal clustering using fuzzy logic (DUCF) [33] calculates the cluster radius of each node and defines the unequal cluster size. It uses fuzzy logic to decide the size of the cluster and perform the $\mathrm{CH}$ selection. It requires residual energy, distance to BS, and node degree to calculate the output (chance value) parameter. It utilizes another 
set of inputs (distance to BS and node degree) to generate cluster size. In contrast to other protocols that use only one output parameter, DUCF considers cluster radius and limit for the number of member nodes simultaneously to finalize $\mathrm{CHs}$. It broadcasts different messages for an unusual purpose.

DUCF shows the advantage of restricting the size of each cluster in terms of the stability of the network and also the longevity of the network. DUCF restricts the number of member nodes for each cluster, which may not appropriately work for some of the clusters and result in the premature death of nodes.

Energy-efficient fuzzy-based scheme for unequal multihop clustering (EEFUC) [34] performs clustering based on fuzzy logic techniques. It utilizes a multi-hop technique to transmit data to BS. The unequal clustering is the basis to form different clusters for data aggregation. The fuzzy logic architecture performs clustering in four stages: competition radius evaluation, $\mathrm{CH}$ calculation, $\mathrm{CM}$ grouping, and determination of relay nodes. EEFUC applies fuzzy logic technique with various input parameters, such as distance to BS, distance to $\mathrm{CH}$, residual energy, and delay distance at different stages.

In [35], the author proposes challenges in handling big data for WSNs. The large volume of data in WSNs introduces many challenges. Data aggregation tasks become a critical task for such a scenario. The proposed work classifies the challenges and explains many analytics tools for WSNs.

Fuzzy-based energy-efficient clustering approach (FEECA) [36] demonstrates a fuzzy logic-based clustering approach for WSNs. The proposal defines the fuzzy rules to select optimal cluster head candidates. FEECA selects the master $\mathrm{CH}$ node from the set of optimal $\mathrm{CHs}$. The diagonal division of the area of interest reduces the cost of communication. The decision for best $\mathrm{CH}$ takes place based on four parameters: remaining energy, average distance, the likelihood of $\mathrm{CH}$, and communication quality.

Power Efficient and Adaptive Latency (PEAL) [37] explains the multi-path clustering protocol for WSNs. It handles the trade-off between network lifetime and transmission latency. The simulation result shows that PEAL extends $47 \%$ network lifetime as compared to LEACH protocol. The protocol works in two phases: cluster set-up phase and steadystate phase.

The many state-of-the-art protocols [38-42] use fuzzy logic to perform clustering for WSNs.

\section{Network Model}

The network model describes the sensor node's placement in the area. Consider a square area for the deployment of $\mathrm{n}$ sensor nodes. Nodes send data via a wireless medium. Each round of algorithm selects a certain number of cluster heads and performs clustering. Cluster size is different and per the capability of the $\mathrm{CH}$. An extraordinary node called base station (BS) collects the data from different $\mathrm{CHs}$ in a multi-hop fashion. The BS location is in the center of the area/corner of the field and does not change. Nodes are assigned a unique ID to perform communication. The ID will remain the same for the entire duration of execution.

\subsection{Assumptions}

Sensor nodes have their limitations, so algorithm formulation adopts certain restrictions.

- The node location is a crucial parameter for the algorithm's analysis and thus assumes random deployment;

- The configuration of the nodes in the network is similar;

- Assume the same initial energy for each node;

- The node's position value is constant in each scenario of the network;

- The base station, centered in the area or positioned in the corner, has unrestricted power;

- The sink will remain stable for the entire protocol execution round;

- The ability of sensor nodes is limited in terms of liveliness; 
- Received signal strength indicator (RSSI) is utilized to determine the distance value between nodes.

\subsection{Energy Model}

The radio energy model of [29] is the standard for most of the clustering algorithms in WSNs, so consider it for different implementation activity (Figure 1).

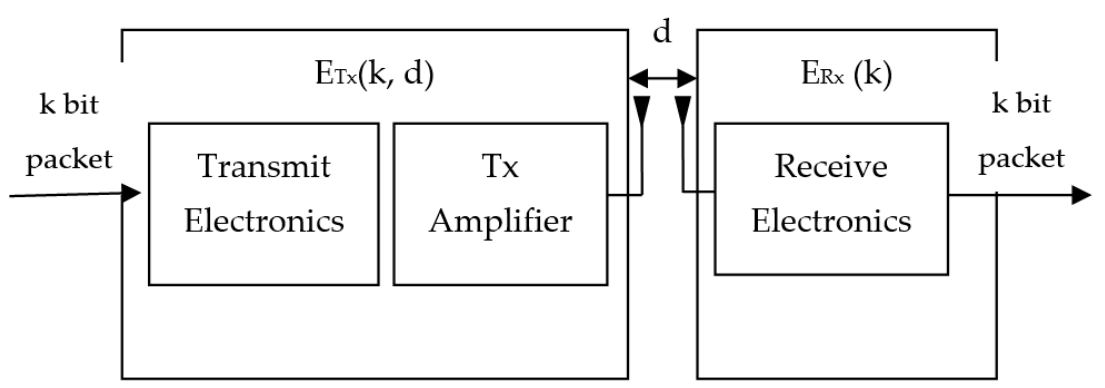

Figure 1. Radio energy model.

Equation (2) shows the energy spent in data transmission:

$$
E_{T}(l, d)=\left\{\begin{array}{l}
E_{\text {elec }} * l+E_{f s} * l * d^{2} \text { if } d<d_{0} \\
E_{\text {elec }} * l+E_{m p} * l * d^{4} \text { if } d \geq d_{0}
\end{array}\right.
$$

where $d$ and $l$ are distance measurement value and data size, respectively.

Equation (3) expresses the energy spent on receiving purposes:

$$
E_{R}=E_{\text {elec }} * l
$$

where $E_{\text {elec }}$ is the value of energy to run the electronic circuitry, and $E_{f s}$, and $E_{m p}$ stand for free-space amplifier energy and multipath amplifier energy, respectively.

Equation (4) illustrates the threshold value of distance $\left(d_{0}\right)$ :

$$
d_{0}=\sqrt{\frac{E_{f s}}{E_{m p}}}
$$

\section{Proposed Algorithm}

Clustering preserves the energy expenditure of the network. A single combination of input parameters does not decide $\mathrm{CHs}$ properly, resulting in network performance and lifetime degradation. The proposed protocol (FFMCP) defines and further uses a different set of parameters relevant for $\mathrm{CH}$ selection. FFMCP improves the performance by using multiple combinations of input parameters for $\mathrm{CH}$ nomination. Consider the hierarchy of two levels for data routing and assume that the first level performs $\mathrm{CH}$ selection and the second layer handles the task of data routing. After sensing the environmental data, member nodes send data to the $\mathrm{CH}$ for onward transmission to the BS. FFMCP considers the modalities of a fuzzy inference system (FIS) to define the complete working properly.

Fuzzy logic is used for the decision-making of unclear events; the results of these events can not be labeled "yes" and "no" or "true" and "false". It mimics the decisionmaking of humans; there may be possible outcomes between "yes" and "no". It primarily consists of four modules, shown in Figure 2 below: 


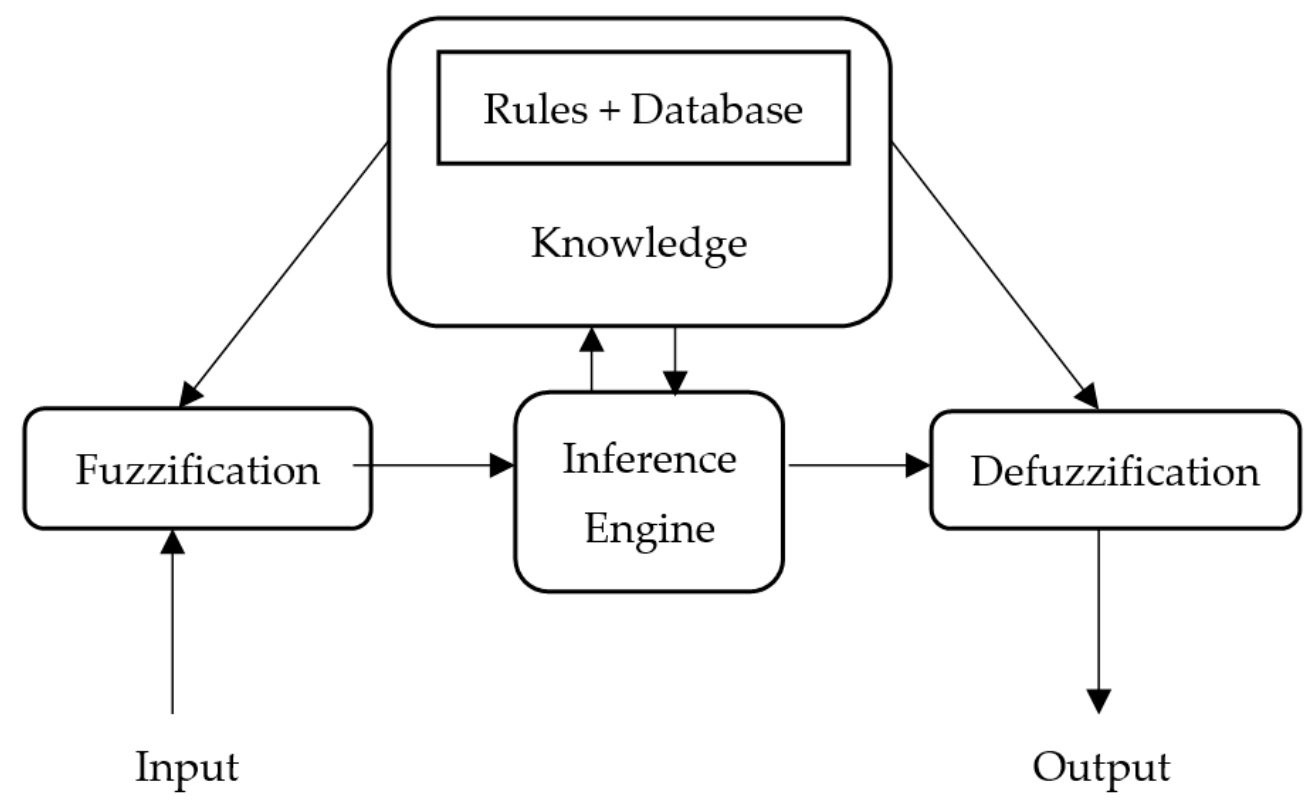

Figure 2. Fuzzy logic system.

Fuzzification: in this module, crisp input is transformed in to fuzzy sets based on linguistic terms. Each variable of linguistics is quantified by the membership function, to determine the suitable range of input.

Knowledge: this module consists of rule-based knowledge that is provided by the experts or a rigorous evaluation of the set of linguistic rules. It requires database knowledge for determining control and management rules.

Inference Engine: it has a function for determining the true value and rules to interpret the reasoning, for "if-then" logic. As an example, if the energy of the sensor node is high, then there is a strong probability for this sensor node to be the $\mathrm{CH}$.

Defuzzification: the module transforms fuzzy sets acquired from the inference engine in to crisp output values, having proper weight with the center of gravity.

The execution of the protocol takes place for a predefined number of rounds. Two different combinations of input-output parameters are responsible for $\mathrm{CH}$ selection. Tables 1 and 2 describe the input variables, output variables, and relationships among variables required for chance value calculations. FFMCP uses multiple chance values during the $\mathrm{CH}$ selection process.

Table 1. Fuzzy "if-then" mapping rule for chance 1.

\begin{tabular}{ccc}
\hline Residual Energy & Count & Chance 1 \\
\hline Low & Low & Verylow \\
Medium & Low & Low \\
High & Low & Medium \\
Low & Medium & Low \\
Medium & Medium & Medium \\
High & Medium & Medium \\
Low & High & Medium \\
Medium & High & High \\
High & High & Veryhigh \\
\hline
\end{tabular}


Table 2. Fuzzy "if-then" mapping rule for chance 2.

\begin{tabular}{ccc}
\hline Residual Energy & MCH & Chance 2 \\
\hline Low & Far & Very small (VS) \\
Medium & Far & Small (S) \\
High & Far & Rather small (RS) \\
Low & Medium & Mediumsmall (MS) \\
Medium & Medium & Medium (M) \\
High & Medium & Mediumlarge (ML) \\
Low & Close & Ratherlarge (RL) \\
Medium & Close & Large (L) \\
High & Close & Verylarge (VL) \\
\hline
\end{tabular}

\subsection{Opening Phase}

The opening phase consists of three major sections. The first phase deals with information collection and sharing, the second phase performs distance calculation, and the third phase performs degree and range calculation.

\subsubsection{Information Collection and Sharing}

Nodes are deployed randomly in WSNs and should share the location and other information with neighboring nodes. Sensor nodes broadcast messages to inform the location and working characteristics of the proposed protocol.

\subsubsection{Distance Calculation}

After the node's deployment in the region of interest, BS broadcasts the message to evaluate the BS distance from sensor nodes. The signal strength indicator is the parameter to perform distance calculation of sensor nodes. The difference of distance from the BS gives input to calculate the distance between two sensor nodes. The following equation shows the distance evaluation:

$$
d_{z}=\left|d_{a}-d_{b}\right|
$$

where $d_{z}$ is the distance between two nodes, and $d_{a}$ and $d_{b}$ are the maximum and minimum distances of a node from $B S$, respectively.

\subsubsection{Degree and Range Calculation}

The degree of a node tells about the neighbor density of a sensor node and has significant importance. Further range of each sensor node is as shown below:

$$
C R_{i}\left(S_{i}\right)=\left(1-q \times\left(\frac{M A_{d}-D B S\left(S_{i}\right)}{M A_{d}-M I_{d}}\right) \times R\right)
$$

where $R$ = range, $q$ = constant parameter, $M I_{d}=$ the minimum distance of a sensor node from $B S, M A_{d}=$ the maximum distance of a sensor node from $B S$, and DBS $\left(S_{i}\right)=$ distance of a sensor node from $B S$.

\subsection{Set-Up Phase}

The set-up phase works in four parts. The first part is responsible for the node's information advertisement, the second performs tentative $\mathrm{CH}$ selection, the third carries out final $\mathrm{CH}$ selection, and the fourth part handles cluster formation.

\subsubsection{Advertisement Phase}

The different information of a sensor node is distributed to the neighboring nodes in the advertisement phase. Each sensor node broadcasts three parameters, namely ID, competition radius, and sensor energy to other nodes in the communication range and finally decides the tentative $\mathrm{CHs}$. Each sensor node maintains two separate tables for retaining network information. The first table maintains the self-information of each node 
while the second table keeps the information of the other neighboring nodes. Self attributes of a node are location, range, and ID of a node.

\subsubsection{Tentative $\mathrm{CH}$ Selection Phase}

We apply a fuzzy C-mean clustering approach to select the tentative $\mathrm{CH}$ nodes [43]. Each sensor node has some membership value in all the clusters; a sensor can belong to every group with a different membership value. For every sensor, the total sum of the membership value of all the clusters is 1 . Membership value depends on the distance between cluster centroid and data point. The lesser the distance value is, the higher the membership value, and vice-versa.

$C=\left\{c_{1}, c_{2}, \ldots \ldots c_{k}\right\}$ is the set of the centroids of $k$ number of clusters, $U=\left\{\mu_{i j}\right\}_{n^{*} k}$ is membership matrix and $\mu_{i j}$ is the membership degree to which observation $i^{\text {th }}$ node $p_{i}$ belongs to cluster having a centroid $c_{i}$. The aim is to minimize the objective function present in Equation (7) by FCM technique:

$$
J(U, C)=\sum_{j=1}^{k} \sum_{i=1}^{n} \mu_{i j}^{m}\left\|p_{i}-c_{i}\right\|^{2}
$$

where $\sum_{j=1}^{K} \mu_{i j}=1 \forall \mathrm{i}, m$ is a fuzzifier that is constant and controls the degree of fuzziness; it ranges between $1<m<\infty$. The degree of membership for the $i^{\text {th }}$ node in $j^{\text {th }}$ cluster is calculated by Equation (8).

$$
\mu_{i j}=\left[\sum_{q=1}^{K}\left(\frac{\left\|p_{i}-c_{j}\right\|}{\left\|p_{i}-c_{q}\right\|}\right)^{\frac{2}{m-1}}\right]^{-1}
$$

The centroid point of each cluster in iteration is updated and is calculated by Equation (9).

$$
\left\lceil\sum_{i=1}^{n} \mu_{i k}^{m} P_{k}\right\rceil
$$

\subsubsection{Final CH Selection Phase}

Algorithm 1 describes the detailed working of the FFMCP method. The inputs of Algorithm 1 are the number of rounds (n_round), deployment area, probability, the position of the sink (sink_p), the initial energy of nodes (initial_e), range (c_range), number of nodes (n_nodes), and type of nodes (t_node). The outputs of Algorithm 1 are a set of CHs and a set of alive nodes. Line1 performs parameter initialization. FFMCP executes for $n \_$round rounds. In each execution round, Algorithm 1 uses the degree and competition range for different types of evaluations. Lines $4-8$ perform to check for alive nodes. The proposed algorithm utilizes two different combinations of input-output parameters for the $\mathrm{CH}$ chance value. Rounds $4,7,11, \ldots$ consider residual energy and count of tentative $\mathrm{CH}$ nodes to calculate the chance value. Rounds $2,5,8, \ldots$ do not perform the $\mathrm{CH}$ selection and uses the alive $\mathrm{CHs}$ of the previous round. Rounds $3,6,9, \ldots$ use the energy and nearest $\mathrm{CH}$ distance to calculate the $\mathrm{CH}$ chance value. Nodes perform maximum energy saving since FFMCP consider energy in each round for $\mathrm{CH}$ chance value calculation. Initial $\mathrm{CHs}$ are selected using the fuzzy C-mean (FCM) clustering approach in round 1. Lines 3-25 and lines 29-46 show pseudo-code for first clustering and second clustering. In lines 26-28, data transmission takes place using previous alive CHs. The design of fuzzy inference system and defuzzification method is carried out using the Mamdani inference system. Figure 3 shows the detailed working of Algorithm 1. Each round of Algorithm 1 selects $\mathrm{CHs}$ based on fuzzy input parameters. 


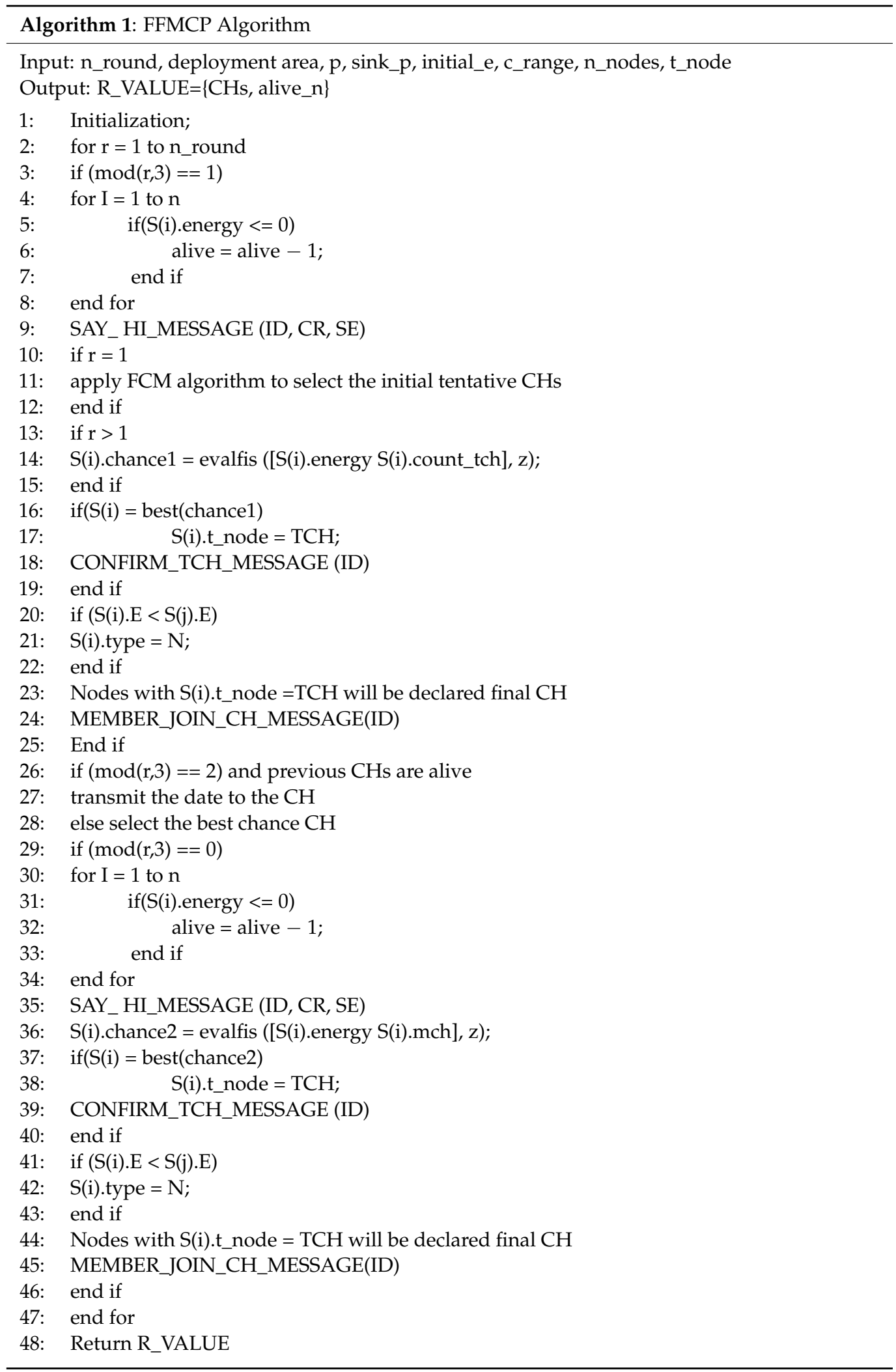




\begin{tabular}{|c|c|c|c|c|c|c|c|c|}
\hline Round-i & Round-ii & Round-iii & Round-iv & Round-v & Round-vi & Round-vii & Round-viii & $\ldots$ \\
\hline $\begin{array}{l}\text { I- } \\
\text { Clustering }\end{array}$ & $\begin{array}{l}\text { II- } \\
\text { Clustering }\end{array}$ & $\begin{array}{l}\text { III- } \\
\text { Clustering }\end{array}$ & $\begin{array}{l}\text { I- } \\
\text { Clustering }\end{array}$ & $\begin{array}{l}\text { II- } \\
\text { Clustering }\end{array}$ & $\begin{array}{l}\text { III- } \\
\text { Clustering }\end{array}$ & $\begin{array}{l}\text { I- } \\
\text { Clustering }\end{array}$ & $\begin{array}{l}\text { II- } \\
\text { Clustering }\end{array}$ & $\ldots$ \\
\hline \multicolumn{2}{|c|}{ I-Clustering } & & \multicolumn{2}{|c|}{ II-Clustering } & & \multicolumn{3}{|c|}{ III-Clustering } \\
\hline \multicolumn{2}{|c|}{$\begin{array}{l}\text { Calculate range and } \\
\text { degree }\end{array}$} & & \multirow{7}{*}{\multicolumn{2}{|c|}{$\begin{array}{l}\text { Previous CHs are alive } \\
\text { transmit the date to the } \\
\mathrm{CH} \text { else select the best } \\
\text { chance } \mathrm{CH}\end{array}$}} & & \multicolumn{3}{|c|}{ Calculate range and degree } \\
\hline \multicolumn{2}{|c|}{$\begin{array}{l}\text { Line } 14 \text { of Algorithm } 1 \\
\text { calculates chance } 1\end{array}$} & & & & & \multicolumn{3}{|c|}{$\begin{array}{l}\text { Line } 36 \text { of Algorithm } 1 \\
\text { calculates chance } 2\end{array}$} \\
\hline \multicolumn{2}{|c|}{$\begin{array}{l}\text { Table } 1 \text { defines fuzzy } \\
\text { rules for the calculation } \\
\text { of chance } 1\end{array}$} & & & & & \multicolumn{3}{|c|}{$\begin{array}{l}\text { Table } 2 \text { defines fuzzy rules } \\
\text { for the calculation of chance } 2\end{array}$} \\
\hline \multicolumn{2}{|c|}{$\begin{array}{l}\text { I-Clustering uses count } \\
\text { of tentative CH nodes } \\
\text { and residual energy as } \\
\text { fuzzy input variables }\end{array}$} & & & & & \multicolumn{3}{|c|}{$\begin{array}{l}\text { II-Clustering uses residual } \\
\text { energy and nearest CH } \\
\text { distance as fuzzy input } \\
\text { variables }\end{array}$} \\
\hline \multicolumn{2}{|c|}{$\begin{array}{l}\text { Estimate tentative } \mathrm{CH} \\
\text { using line } 17 \text { of } \\
\text { Algorithm } 1\end{array}$} & & & & & \multicolumn{3}{|c|}{$\begin{array}{l}\text { Estimate tentative } \mathrm{CH} \text { using } \\
\text { line } 38 \text { of Algorithm } 1\end{array}$} \\
\hline \multicolumn{2}{|c|}{$\begin{array}{l}\text { Highest energy node is } \\
\text { declared as final } \mathrm{CH}\end{array}$} & & & & & \multicolumn{3}{|c|}{$\begin{array}{l}\text { Highest energy node is } \\
\text { declared as final } \mathrm{CH}\end{array}$} \\
\hline \multicolumn{2}{|c|}{$\begin{array}{l}\mathrm{CH} \text { gathers data from } \\
\text { member nodes for } \\
\text { onward transmission to } \\
\text { BS }\end{array}$} & & & & & \multicolumn{3}{|c|}{$\begin{array}{l}\mathrm{CH} \text { gathers data from } \\
\text { member nodes for onward } \\
\text { transmission to BS }\end{array}$} \\
\hline
\end{tabular}

Figure 3. Detailed explanation of Algorithm 1.

Figures 4-8 show the membership function of the node's remaining energy, tentative $\mathrm{CH}$ count, minimum distance to $\mathrm{CH}$, chance 1 , and chance 2 values, respectively.

Each node calculates chance value using the rules of Tables 1 and 2 and further finalizes $\mathrm{CH}$ with maximum chance value.

Due to uncertainty, FIS supports selecting the CHs whose fitness value is superior. FIS development took place to perform the $\mathrm{CH}$ selection and supervise the member nodes to join the suitable $\mathrm{CH}$. The key benefit of the FIS is the low computational complexity. FFMCP selects $\mathrm{CHs}$ having a higher chance value in a particular round of algorithms.

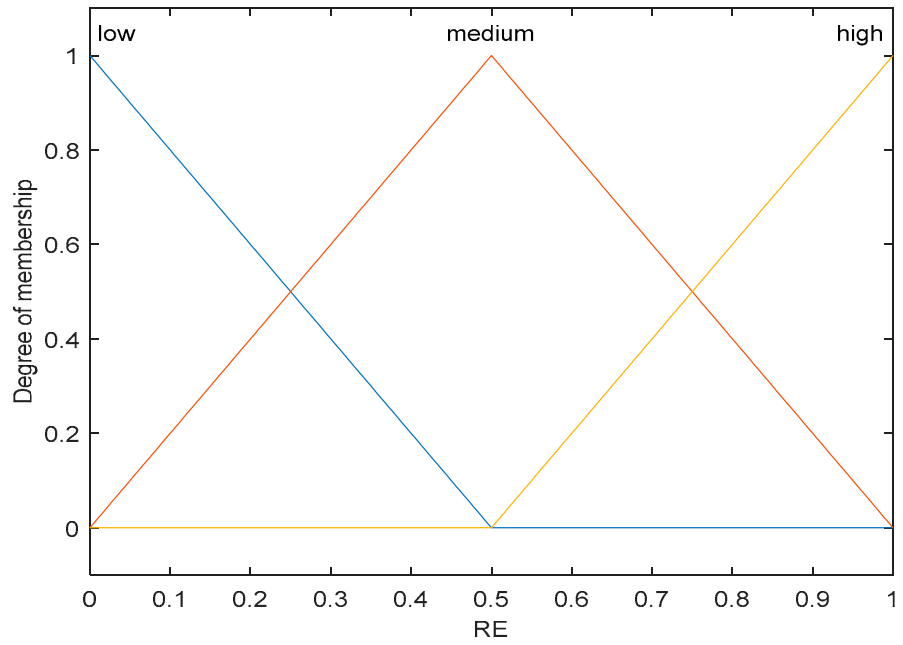

Figure 4. Membership function for residual energy. 


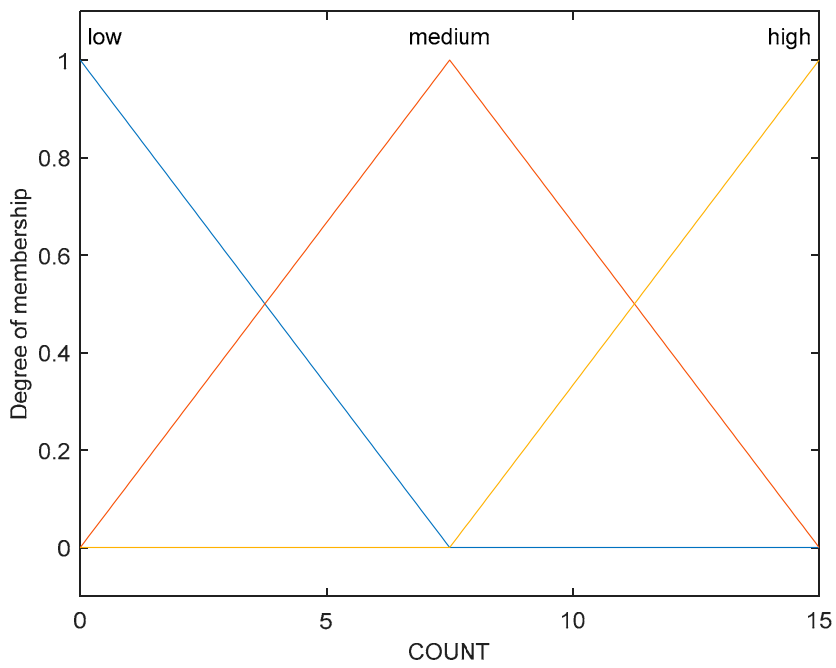

Figure 5. Membership function for count.

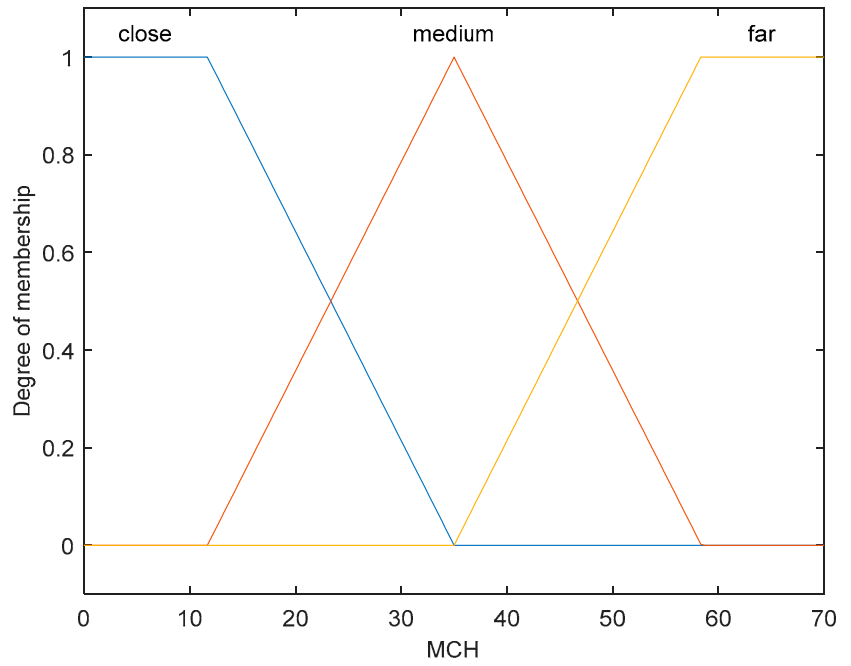

Figure 6. Membership function for min $\mathrm{CH}$ distance.

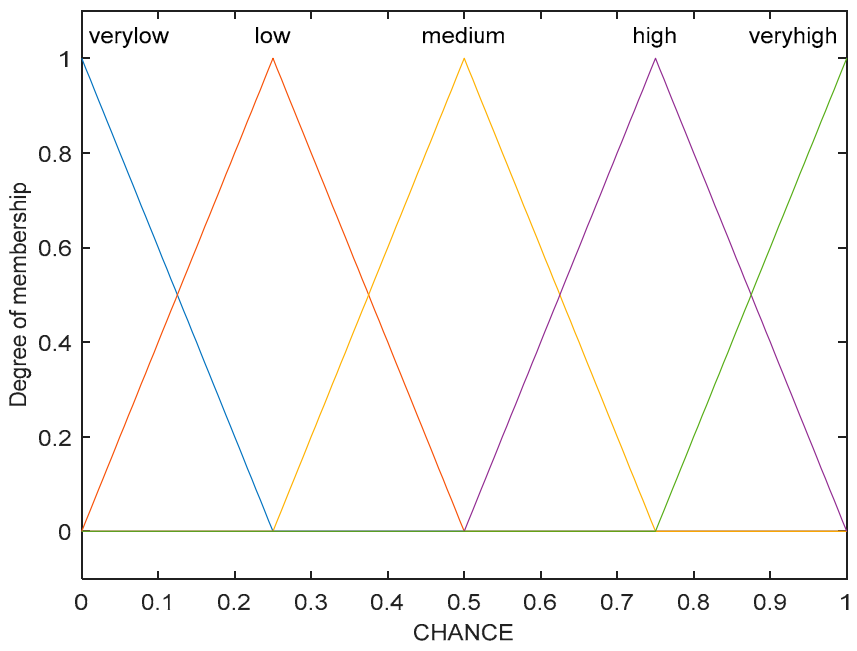

Figure 7. Membership function for chance 1. 


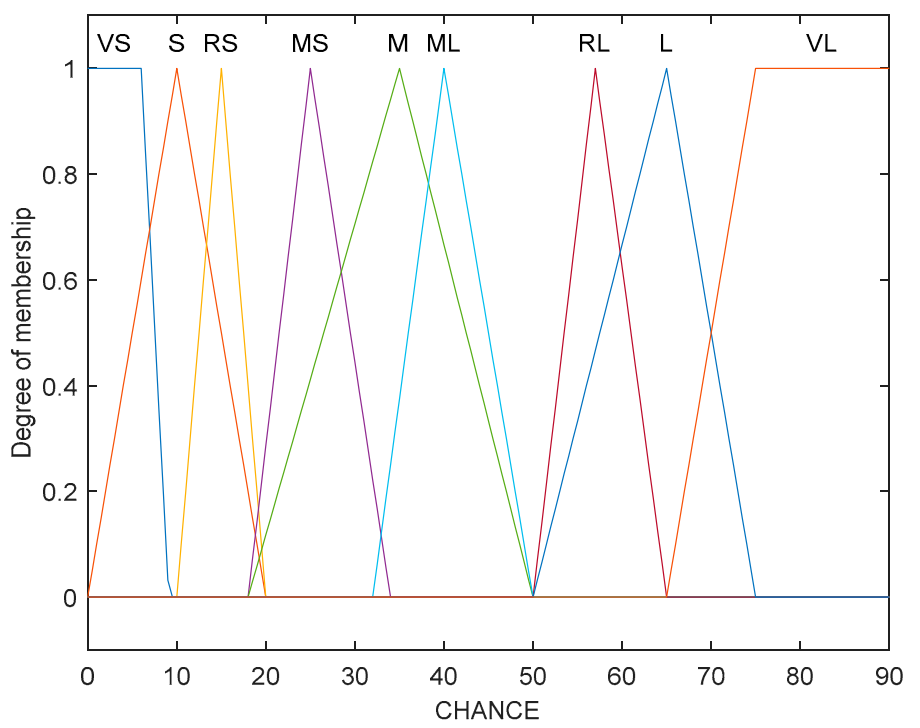

Figure 8. Membership function for chance 2.

The range of input variables for residual energy, count of tentative $\mathrm{CHs}$, and minimum distance to $\mathrm{CH}$ is $(0,1),(0,15)$, and $(0,70)$, respectively. The range of output variables for chance 1 and chance 2 is $(0,1)$ and $(0,100)$ respectively. The linguistic variables of the input values (RE, COUNT) are low, medium, and high; linguistic variables of the input value $(\mathrm{MCH})$ are close, medium, and far. The linguistic variables of the output value (chance 1) are very low, low, medium, high, and very high; linguistic variables of the output value (chance 2) are very small, small, rather small, medium small, medium, medium large, rather large, large, and very large.

Inference engine based on fuzzy logic: it is complex and difficult to design a mathematical model for a changing WSN scenario. It is not easy to extend the mathematical model, which is designed for static WSN scenarios and can cater to some specific requirements. The value of environmental variables changes frequently, so the WSN deployment scenario becomes more dynamic. Energy, proximity, and inter-node distance are popular variables for controlling and monitoring different WSN scenarios. A fuzzy inference engine supports the uncertainty management of monitoring variables and enhances the accuracy of the results. Fuzzy rule-based systems are significant because of the approximate reasoning when there is a degree of uncertainty and imprecision in the data in the reasoning process. Membership functions are inputs and fuzzy rules perform decision-making for the inference engine.

Membership functions: membership functions show the truth degree of the variables (input/output) and represent quantitative measures through a set of vaguely defined values. The tuning of the membership function and reduction in system design time occurs for parameterizable functions. The optimization of parameters for proper $\mathrm{CH}$ selection requires time and computational cost. FFMCP performs several simulations to finalize the input parameter's membership functions. For example, intersection points determine the peak value of the membership function. Membership function tuning takes place with the help of fuzzy results to cover the desired situation. In FFMCP, some membership functions are modified due to the uncertainty of parameters. Proposed work performs simulation rounds and considers network size and node density to tune the membership function. Triangular and trapezoidal membership functions are easy for tuning and suitable to handle network dynamism. The change in the parameter's value is directly related to the desired changes in the two membership functions.

"If-then" rules: there is a set of linguistic rules to map the input parameters with output parameters as given by:

IF X, THEN Y, X represents a group of input parameters (energy level, degree, distance) and connections (NOT, OR, AND), and $\mathrm{Y}$ represents a group of output variables (chance 
value). We have two different combinations of input-output variables. In each group, there are two inputs and one output variable. The output variable corresponds to chance for $\mathrm{CH}$. There are nine different rules in each case to control the uncertainty.

The defuzzification is based on the center of area (COA) method to calculate the crisp value.

Trapezoidal membership function (Equation (10)) is applied for boundary variables and triangular membership function (Equation (11)) for intermediate variables.

$$
\begin{gathered}
\mu_{A}(x)=f(x)=\left\{\begin{array}{c}
0,(x<a) \|(x>d) \\
\frac{x-a}{b-a}, a \leq x \leq b \\
1, b \leq x \leq c \\
\frac{d-x}{d-c}, c \leq x \leq d
\end{array}\right. \\
\mu_{A}(x)=f(x)=\left\{\begin{array}{c}
0, x \leq a \\
\frac{x-a}{m-a}, a<x \leq m \\
\frac{b-x}{b-m}, m<x<b \\
0, x \geq b
\end{array}\right.
\end{gathered}
$$

\subsubsection{Cluster Formation Phase}

Each node selects the nearest $\mathrm{CH}$ and forms the cluster by broadcasting the message in the competition range using a non-persistent carrier sense multiple access (CSMA) MAC. The message announcement contains the ID of the $\mathrm{CH}$. After receiving the message, sensor nodes finalize suitable $\mathrm{CH}$ for cluster formation. The smaller the communication range, the smaller the cluster size will be, saving the energy efficiently. Once the cluster formation completes, $\mathrm{CH}$ performs data collection from the cluster member using the TDMA schedule. TDMA execution performs with the help of members of the $\mathrm{CH}$. TDMA also controls the collision during data transmission. It schedules the member nodes using the sleep-wake protocol; member nodes will save energy by going to a sleep state once the data transmission work finishes.

\subsection{Data Transmission Phase}

Data transmission takes place after the set-up phase finishes execution. $\mathrm{CH}$ uses the TDMA schedule to transmit data to the BS. Multiple communications take place during data transmission. Cluster members send data to the $\mathrm{CH}$ via intra-cluster communication and $\mathrm{CHs}$ collect the data. The data collected by the $\mathrm{CH}$ is further transmitted to the $\mathrm{BS}$ via inter-cluster communication.

Equation (12) approximates total energy usage for the cluster formation $\left(E C_{\text {intra }}\right)$ and the multihop $\left(E C_{\text {inter }}\right)$ transmitting to BS in one complete round.

$$
E_{\text {tot }}=E C_{\text {intra }}+E C_{\text {inter }}
$$

The $E C_{\text {intra }}$ includes the energy used in transmitting from cluster member to its $\mathrm{CH}$ $\left(E C H_{\text {member }}\right)$, energy used to receive data at $\mathrm{CH}\left(E C H_{\text {receive }}\right)$, and also data aggregate $\left(E_{D A}\right)$ from all its members for forwarding purposes. It can be shown in Equation (13) as:

$$
\begin{gathered}
E C_{\text {intra }}=E C H_{\text {member }}+E C H_{\text {receiver }}+N \times E_{D A} \\
E C H_{\text {member }}=\sum_{j=1}^{N} E_{T_{X}}\left(k, C M_{j}, C H\right) \\
E C H_{\text {receiver }}=N \times E_{R_{X}}(k)
\end{gathered}
$$


The $E C_{\text {inter }}$ only requires enough energy to forward information from all the $\mathrm{CH}$ through multiple hops to $B S$ as in Equation (16):

$$
\begin{gathered}
E C_{\text {inter }}=E_{T_{X}}\left(k, C H, C H_{1}\right)+\sum_{i=1}^{m} E_{T_{X}}\left(k, C H_{i-1}, C H_{i}\right) \\
+E_{T_{X}}\left(k, C H_{m}, B S\right)+m E_{R_{X}}
\end{gathered}
$$

Here, transmission order is from $\mathrm{CH}_{i-1}$ to $\mathrm{CH}_{i}$, with $\mathrm{CH}_{1}$ as the initial $\mathrm{CH}$ of $\mathrm{m}$ intermediate $\mathrm{CHs}$.

Time synchronization is an essential feature for the functioning of WSNs. Many pieces of research regarding time synchronization have been accomplished in recent years. Numerous protocols are proposed [44-46] for this problem. The clock of the sensor nodes should converge quickly to synchronize the different operations among sensor nodes. In [44], the author proposed three protocols for time synchronization, with a common goal of clock convergence. FFMCP protocol can use the protocol of [44] to perform the different operations in a synchronized manner; due to lesser message transmissions, this will save the energy of sensor nodes.

\section{Comparative Analysis of Result and Simulation Work}

Proper algorithm analysis and performance comparison in different network scenarios is the key aim of the simulation. All simulations for evaluation of performance carry out using the Matlab tool. The performance of FFMCP with that of LEACH, EAUCF, FLECH, DUCF, and EEFUC in terms of tenth node death (TND), half node death (HND), remaining energy after 800 rounds (E_800), and average energy spent per round (AVG_PR) is plotted in Figures 9-12, respectively. Tables 3-5 show the quantitative details. Simulations perform in three different scenarios, considering the resultant value of the average of 10 different simulations in each case.

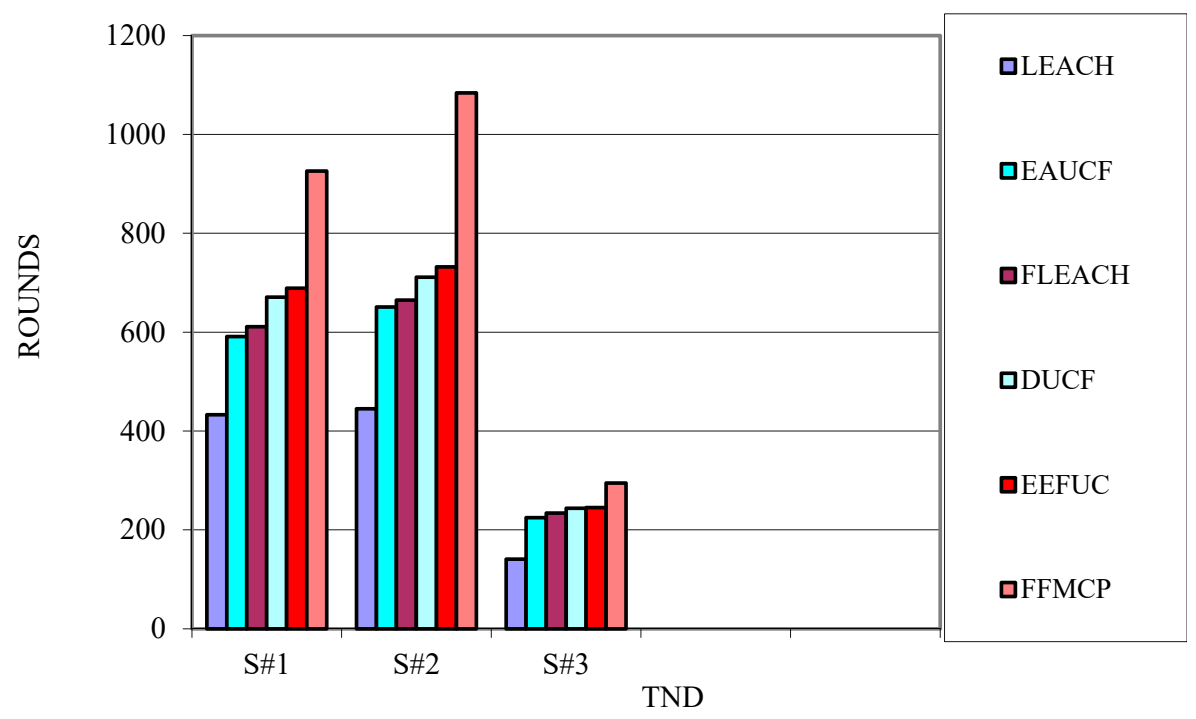

Figure 9. TND in different scenario. 


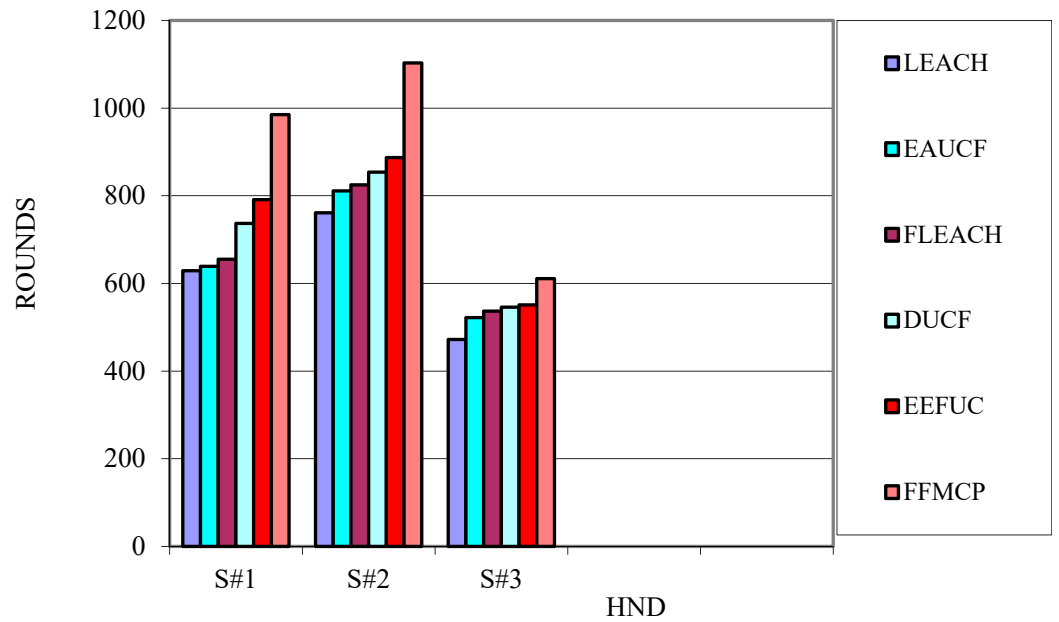

Figure 10. HND in different scenario.

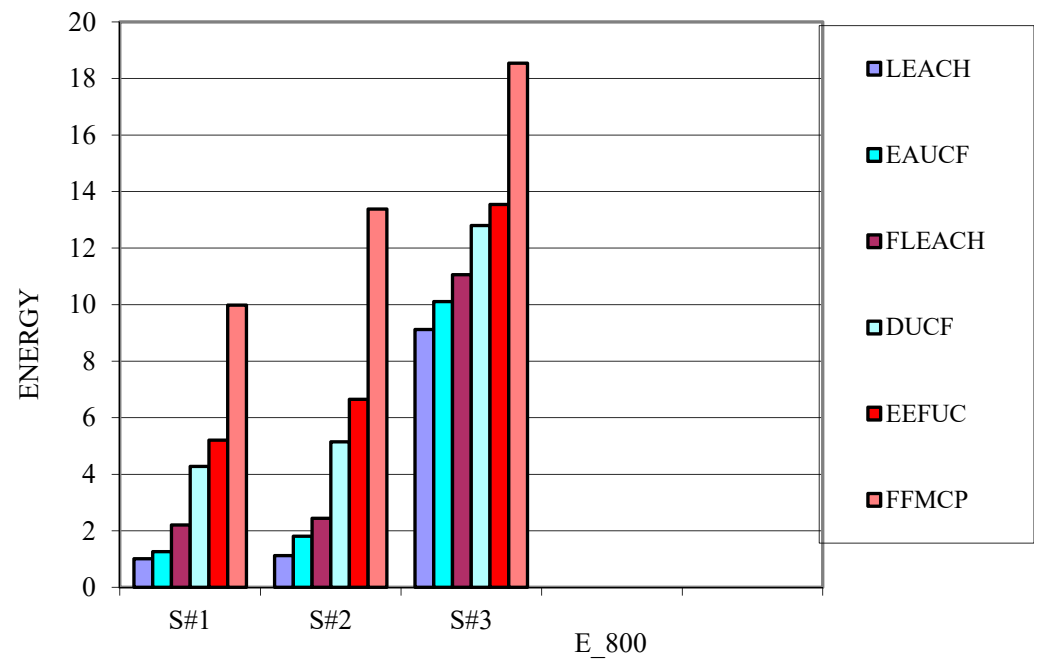

Figure 11. Residual energy after 800 round in a different scenario.

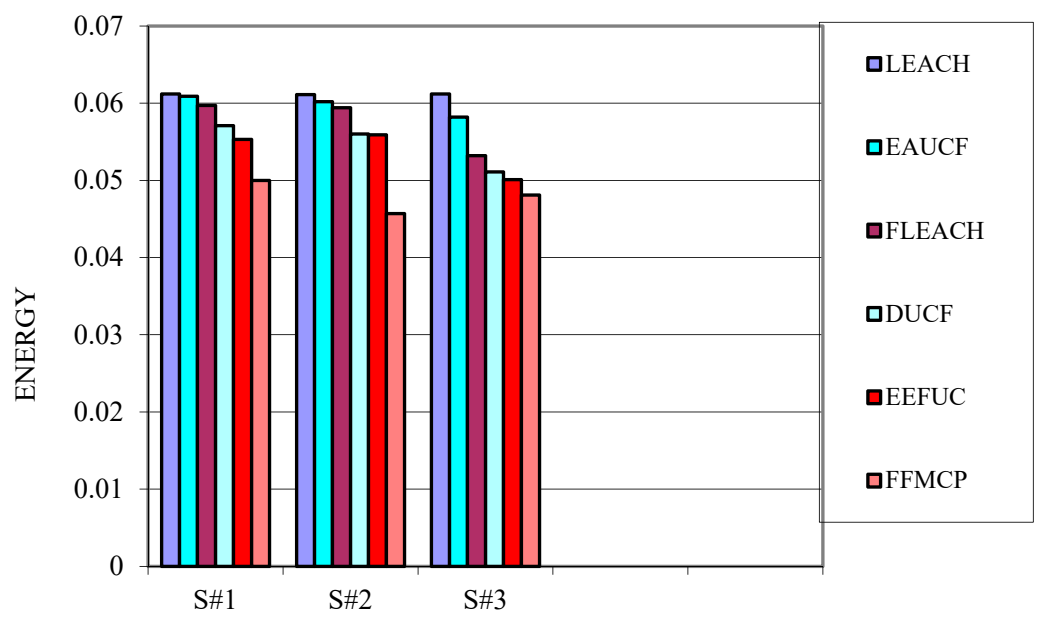

Figure 12. Average energy spent per round. 
Table 3. Performance of scenario 1.

\begin{tabular}{ccccc}
\hline Algorithm & TND & HND & E_800 & AVG_PR \\
\hline LEACH & 433 & 629 & 1.01 & 0.0612 \\
EAUCF & 591 & 639 & 1.26 & 0.0609 \\
FLECH & 611 & 665 & 2.21 & 0.0597 \\
DUCF & 671 & 737 & 4.28 & 0.0571 \\
EEFUC & 689 & 791 & 5.21 & 0.0553 \\
FFMCP & 926 & 985 & 9.98 & 0.0500 \\
\hline
\end{tabular}

Table 4. Performance of scenario 2.

\begin{tabular}{ccccc}
\hline Algorithm & TND & HND & E_800 & AVG_PR \\
\hline LEACH & 445 & 761 & 1.12 & 0.0611 \\
EAUCF & 651 & 811 & 1.81 & 0.0602 \\
FLECH & 665 & 825 & 2.44 & 0.0594 \\
DUCF & 711 & 854 & 5.15 & 0.0560 \\
EEFUC & 732 & 887 & 6.65 & 0.0559 \\
FFMCP & 1084 & 1103 & 13.38 & 0.0457 \\
\hline
\end{tabular}

Table 5. Performance of scenario 3.

\begin{tabular}{ccccc}
\hline Algorithm & TND & HND & E_800 & AVG_PR \\
\hline LEACH & 141 & 472 & 9.12 & 0.0612 \\
EAUCF & 225 & 522 & 10.11 & 0.0582 \\
FLECH & 234 & 537 & 11.06 & 0.0532 \\
DUCF & 244 & 546 & 12.8 & 0.0511 \\
EEFUC & 245 & 551 & 13.54 & 0.0501 \\
FFMCP & 295 & 611 & 18.54 & 0.0481 \\
\hline
\end{tabular}

FFMCP establishes its importance and produces better results than other protocols (LEACH, EAUCF, FLECH, DUCF, and EEFUC). FFMCP discards the analysis for first node death and last node death. The network performance does not suffer much due to the death of a small number of nodes. The network performance decreases significantly after $50 \%$ of the nodes die. The simulation results analyze the effectiveness of FFMCP for the following three scenarios:

- First scenario, S\#1 (Figure 13) considers the network area of (200*200) with the base station located at $(100,100)$ and the initial energy of each node as 0.5 joules;

- Second scenario, S\#2 (Figure 14) has an area of (100*100), base station location as (50, 50 ) initial energy of each node as 0.5 joules;

- Third scenario, S\#3 (Figure 15) has an area of (500*500), base station location as (500, 500) initial energy of each node as 5 joules.

The other necessary parameters for our simulation to work in different scenarios are mentioned in Table 6. FFMCP always performs better than the other considered protocols. 


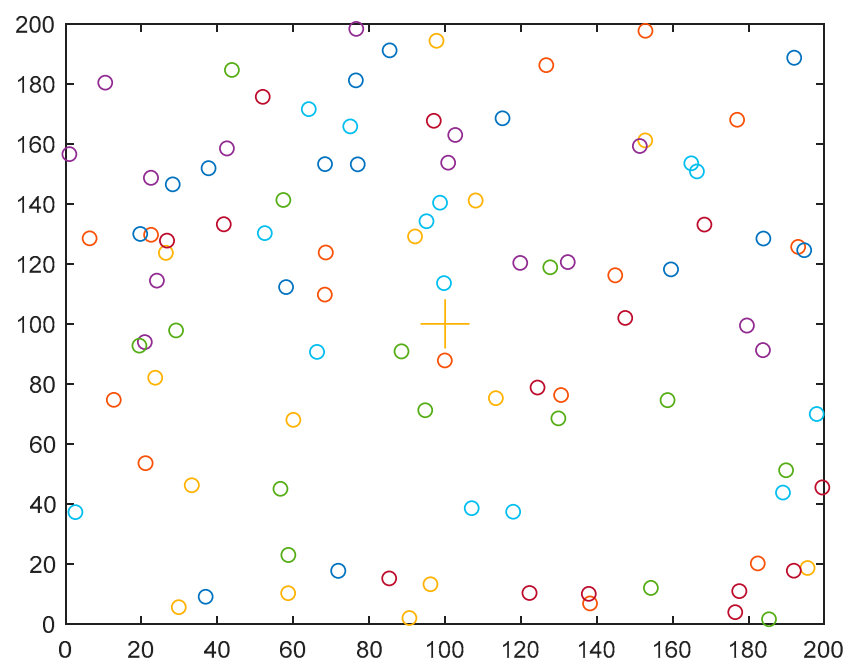

Figure 13. First scenario.

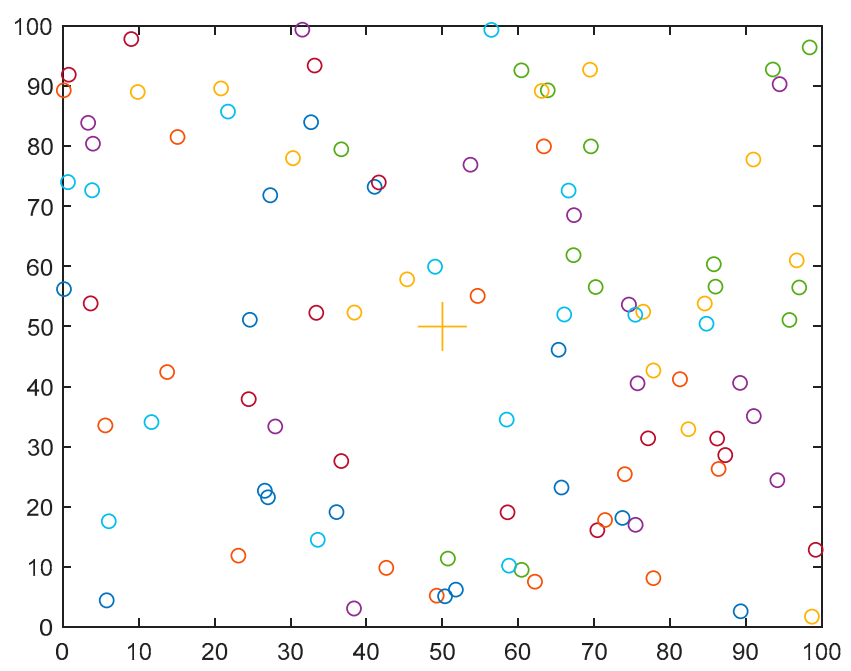

Figure 14. Second scenario.

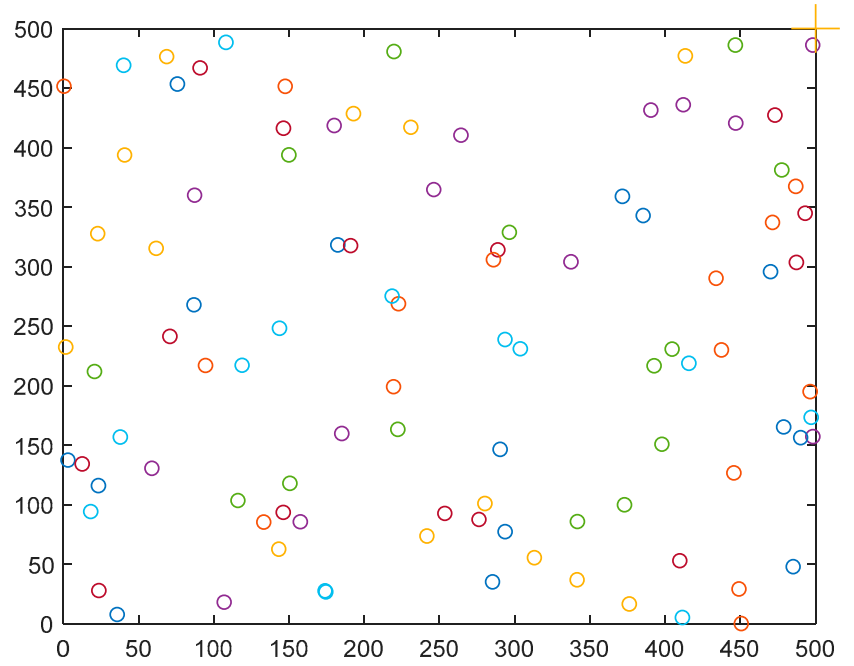

Figure 15. Third scenario. 
Table 6. Parameters considered for simulations.

\begin{tabular}{cc}
\hline \#Parameters & \#Value \\
\hline Nodes totality & 100 \\
$\mathrm{E}_{\mathrm{elec}}$ & $50 \mathrm{~nJ} / \mathrm{bit}$ \\
$\mathrm{E}_{\mathrm{fs}}$ & $10 \mathrm{pJ} / \mathrm{bit} / \mathrm{m}^{2}$ \\
$\mathrm{E}_{\mathrm{mp}}$ & $0.0013 \mathrm{pJ} / \mathrm{bit} / \mathrm{m}^{4}$ \\
$\mathrm{E}_{\mathrm{DA}}$ & $5 \mathrm{~nJ} / \mathrm{bit} / \mathrm{message}$ \\
Datasize & $4000 \mathrm{bits}$ \\
Control message & $200 \mathrm{bits}$ \\
\hline
\end{tabular}

Scenario 1: the deployment of 100 homogeneous (same initial energy) nodes in a large area $\left(200^{*} 200\right)$ for reasonable comparison among protocols is considered. Table 3 demonstrates the performance of scenario1.

TND parameter is $113.9 \%$ better than LEACH, $56.7 \%$ better than EAUCF, $51.6 \%$ better than FLECH, 38\% better than DUCF, and 34.4\% better than EEFUC. HND parameters perform $56.6 \%$ better than LEACH, $54.1 \%$ better than EAUCF, $48.1 \%$ better than FLECH, $33.6 \%$ better than DUCF, and $24.5 \%$ better than EEFUC. The residual energy for FFMCP is eight times more than that of LEACH, seven times that of EAUCF, three times that of FLECH, twice that of DUCF, and $91.6 \%$ better than EEFUC for 800 rounds. The average energy spent per round for FFMCP is $18.3 \%$ less than LEACH, $17.9 \%$ less than EAUCF, $16.2 \%$ less than FLECH, $12.4 \%$ less than DUCF, and 9.6\% less than EEFUC.

Scenario 2: its area is smaller $\left(100^{*} 100\right)$ than scenario 1 but has the same initial energy. The purpose of this scenario is to analyze the behavior of the protocols for small area networks. The performance of the protocols is described in Table 4. FFMCP shows superiority over other protocols under consideration. Table 4 shows different performanceassociated parameters in scenario 2. TND parameter is $143.6 \%$ better than LEACH, $66.5 \%$ better than EAUCF, $63 \%$ better than FLECH, $52.5 \%$ better than DUCF, and $48.1 \%$ better than EEFUC. HND parameters perform $44.9 \%$ better than LEACH, $36 \%$ better than EAUCF, $33.7 \%$ better than FLECH, 29.2\% better than DUCF, and 24.4\% better than EEFUC. The residual energy for FFMCP is much higher than other protocols for 800 rounds. The residual energy for FFMCP is 103.3\% better than LEACH, 83.4\% better than EAUCF, $67.6 \%$ better than FLECH, $44.8 \%$ better than DUCF, and $101.2 \%$ better than EEFUC. The average energy spent per round for FFMCP is $21.4 \%$ less than LEACH, $17.4 \%$ less than EAUCF, 9.6\% less than FLECH, $5.9 \%$ less than DUCF, and $18.2 \%$ less than EEFUC.

Scenario 3: the area is more $(500 * 500)$ as compared to scenario 1 and scenario 2 . The initial energy is also larger than the other two scenarios. The purpose of this scenario is to analyze the behavior of the protocols for large area net works. The performance of the protocols exists in Table 5. FFMCP shows superiority over other protocols under consideration. Table 5 shows different performance-associated parameters in scenario 3. TND parameter is $109.2 \%$ better than LEACH, 31\% better than EAUCF, $26.1 \%$ better than FLECH, $20.9 \%$ better than DUCF, and $20.4 \%$ better than EEFUC. HND parameters perform $29.5 \%$ better than LEACH, $17.1 \%$ better than EAUCF, $13.8 \%$ better than FLECH, $11.9 \%$ better than DUCF, and 10.9\% better than EEFUC. The residual energy for FFMCP is much higher than other protocols for 800 rounds. The average energy spent per round for FFMCP is $25.2 \%$ less than LEACH, $24.1 \%$ less than EAUCF, $23.1 \%$ less than FLECH, $18.4 \%$ less than DUCF, and $3.9 \%$ less than EEFUC.

The simulation work reveals that the FFMCP protocol performs better than other protocols for tenth node death (TND), half node death (HND), and remaining energy after 800 rounds (E_800), and average energy spent per round (AVG_PR). The parameters used for the performance evaluation are popular for WSN clustering. The network performance decreases as the node's energy reduces below a threshold limit. After $10 \%$ of nodes die, the network performance hampers significantly. Data collection and aggregation suffer a lot after $50 \%$ of nodes die. The higher the value of remaining energy after a certain round of algorithm execution, the more useful is the protocol for the real-time scenario. 
Tables 1 and 2 define fuzzy rules for cluster head selection. Each rule considers energy as one parameter. The rule-based fuzzy system controls the energy expenditure of sensor nodes; as a result, the average energy spent per round is the lowest for the proposed protocol. The FFMCP protocol shows a better scalability feature, as it shows significant performance gain in a large-scale scenario.

FFMCP runs a pre-defined number of rounds to draw a box plot. Figures 16-18 show the box plot of the proposed protocol for three different scenarios (S\#1, S\#2, S\#3). The box plots represent the energy distribution of 100 sensor nodes.

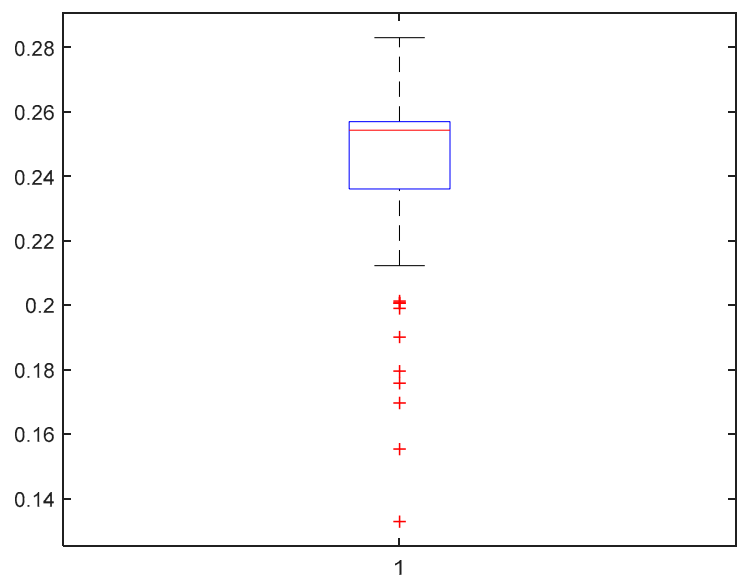

Figure 16. Box plot of node's energy distribution in S\#1.

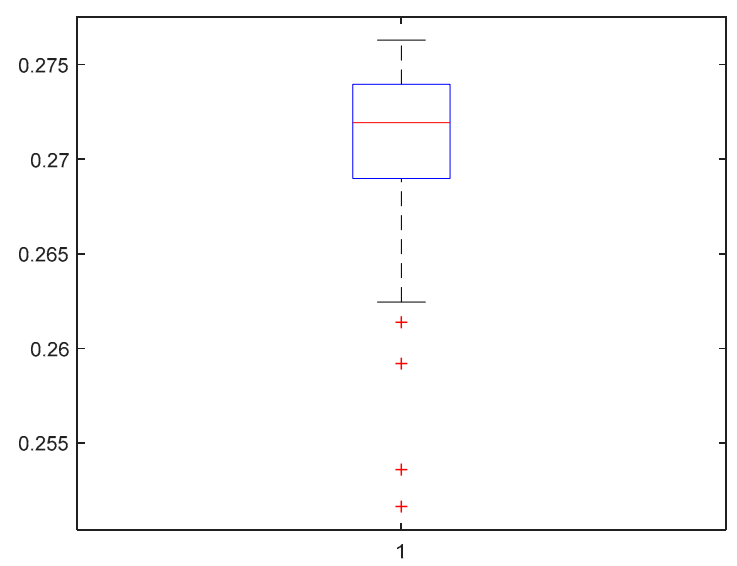

Figure 17. Box plot of node's energy distribution in S\#2.

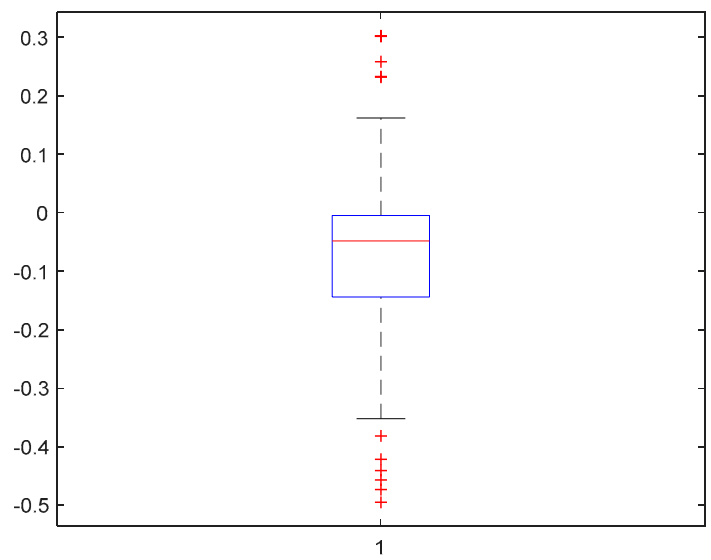

Figure 18. Box plot of node's energy distribution in S\#3. 


\section{Conclusions and Future Works}

Network information of the previous round helps in predicting the better $\mathrm{CH}$ for the next round. The proposal (FFMCP algorithm) is a feed-forward multi-clustering protocol. FFMCP uses a fuzzy inference system to overcome the uncertainties in the value of input parameters. The proposed protocol calculates chance value by using two different sets of input parameters. FFMCP performance is better than the other protocols, as it considers the information of the previous round to calculate the chance value. Residual energy, tentative $\mathrm{CH}$ count, and minimum distance to $\mathrm{CH}$ facilitate to calculate output parameters. FFMCP shows enhanced performance than LEACH, EAUCF, FLECH, DUCF, and EEFUC in each case.

In the future, an analysis of the performance assuming some extraordinary energy harvesting nodes is probable research scope. Node deployment is in a square area; another deployment pattern is also possible. Simulations run for the stable sink, so controlled or pre-determined mobility can also be a future work. More discussions can take place on the number of mobile sensor nodes and their positions.

Author Contributions: Conceptualization, methodology, investigation writing-review, and editing: P.K.M., supervising: S.K.V. All authors have read and agreed to the published version of the manuscript.

Funding: This research received no external funding.

Institutional Review Board Statement: Not applicable.

Informed Consent Statement: Not applicable.

Data Availability Statement: Exclude this statement.

Conflicts of Interest: The authors declare that there are no conflicts of the interest regarding the publication of this article.

\section{References}

1. Chen, Y.-C.; Wen, C.-Y. Distributed Clustering With Directional Antennas for Wireless Sensor Networks. IEEE Sens. J. 2013, 13, 2166-2180. [CrossRef]

2. Babaie, S.; Zadeh, A.K.; Amiri, M.G. The New Clustering Algorithm with Cluster Members bounds for energy dissipation avoidance in wireless sensor network. In Proceedings of the 2010 International Conference On Computer Design and Applications, Qinhuangdao, China, 25-27 June 2010; Volume 2, pp. V2-613-V2-617.

3. Mishra, P.K.; Verma, S.K. A survey on clustering in wireless sensor network. In Proceedings of the 2020 11th International Conferenceon Computing, Communication and Networking Technologies (ICCCNT), Kharagpur, India, 1-3 July 2020; pp. 1-5.

4. Kaur, R.; Sharma, M. An approach to design habitat monitoring system using sensor networks. Int. J. Soft Comput. Eng. 2011, 1, 5-8.

5. Suzuki, M.; Saruwatari, S.; Kurata, N.; Morikawa, H. A high-density earth quake monitoring system using wireless sensor networks. In Proceedings of the 5th International Conference on Bioinformatics and Computational Biology; Association for Computing Machinery: New York, NY, USA, 2007; pp. 373-374.

6. Winkler, M.; Street, M.; Tuchs, K.D.; Wrona, K. Wireless sensor networks for military purposes. In Autonomous Sensor Networks; Springer: Berlin/Heidelberg, Germany, 2012; pp. 365-394.

7. Winkler, M.; Tuchs, K.D.; Hughes, K.; Barclay, G. Theoretical and practical aspects of military wireless sensor networks. J. Telecommun. Inf. Technol. 2008, 2, 37-45.

8. Ko, J.; Lim, J.H.; Chen, Y.; Musvaloiu, E.R.; Terzis, A.; Masson, G.M. MEDiSN:Medical emergency detection in sensor networks. Acm Trans. Embed. Comput. Syst. 2010, 10, 11. [CrossRef]

9. Woznowski, P.; Burrows, A.; Diethe, T.; Fafoutis, X.; Hall, J.; Hannuna, S.; Camplani, M.; Twomey, N.; Kozlowski, M.; Tan, B.; et al. SPHERE: A Sensor Platform for Health care in a Residential Environment. In Designing, Developing, and Facilitating Smart Cities; Springer Science and Business Media LLC: Berlin/Heidelberg, Germany, 2016; pp. 315-333.

10. Rashid, B.; Rehmani, M.H. Applications of wireless sensor networks for urban areas: A survey. J. Netw. Comput. Appl. 2016, 60, 192-219. [CrossRef]

11. Ceriotti, M.; Mottola, L.; Picco, G.P.; Murphy, A.L.; Guna, S.; Corra, M. Monitoring heritage buildings with wireless sensor networks: The torreaquila deployment. In Proceedings of the 2009 International Conference on Information Processing in Sensor Networks, San Francisco, CA, USA, 13-16 April 2009; pp. 277-288.

12. Dong, Q.; Yu, L.; Lu, H.; Hong, Z.; Chen, Y. Design of Building Monitoring Systems Based on Wireless Sensor Networks. Wirel. Sens. Netw. 2010, 2, 703-709. [CrossRef] 
13. Stojkoska, B.L.R.; Trivodaliev, K.V. A review of Internet of Things for smart home: Challenges and solutions. J. Clean. Prod. 2017, 140, 1454-1464. [CrossRef]

14. Suryadevara, N.K. Wireless sensor sequence data model for smart home and IoT data analytics. In Proceedings of the First International Conference on Computational Intelligence and Informatics; Springer: Berlin/Heidelberg, Germany, 2017 ; pp. $441-447$.

15. Kafi, M.A.; Challal, Y.; Djenouri, D.; Doudou, M.; Bouabdallah, A.; Badache, N. A Study of Wireless Sensor Networks for Urban Traffic Monitoring: Applications and Architectures. Procedia Comput. Sci. 2013, 19, 617-626. [CrossRef]

16. Liu, X.-Y.; Zhu, Y.; Kong, L.; Liu, C.; Gu, Y.; Vasilakos, A.V.; Wu, M.-Y. CDC: Compressive Data Collection for Wireless Sensor Networks. IEEE Trans. Parallel Distrib. Syst. 2014, 26, 2188-2197. [CrossRef]

17. Heinzelman, W.B.; Chandrakasan, A.P.; Balakrishnan, H. An application-specific protocol architecture for wireless microsensor networks. IEEE Trans. Wirel. Commun. 2002, 1, 660-670. [CrossRef]

18. Zahedi, A.; Arghavani, M.; Parandin, F.; Arghavani, A. Energy Efficient Reservation-Based Cluster Head Selection in WSNs. Wirel. Pers. Commun. 2018, 100, 667-679. [CrossRef]

19. Deepa, C.; Latha, B. HHSRP: A cluster based hybrid hierarchical secure routing protocol for wireless sensor networks. Clust. Comput. 2017, 2, 1-17. [CrossRef]

20. Huang, J.; Hong, Y.; Zhao, Z.; Yuan, Y. An energy-efficient multi-hop routing protocol based on grid clustering for wireless sensor networks. Clust. Comput. 2017, 20, 3071-3083. [CrossRef]

21. Maddali, B.K. Core network supported multicast routing protocol for wireless sensor networks. IET Wirel. Sens. Syst. 2015, 5 , 175-182. [CrossRef]

22. Mohammed, T.; Kemal, E.T.; Sasan, A.; Shervin, E. Survey of multi path routing protocols for mobile adhoc networks. J. Netw. Comput. Appl. 2009, 32, 1125-1143.

23. Du, R.; Chen, C.; Yang, B.; Lu, N.; Guan, X.; Shen, X. Effective Urban Traffic Monitoring by Vehicular Sensor Networks. IEEE Trans. Veh. Technol. 2015, 64, 273-286. [CrossRef]

24. Younis, O.; Fahmy, S. HEED: A hybrid energy-efficient, distributed clustering approach for adhoc sensor networks. IEEE Trans. Mob. Comput. 2004, 3, 366-379. [CrossRef]

25. Hoang, D.C.; Yadav, P.; Kumar, R.; Panda, S.K. Real-Time Implementation of a Harmony Search Algorithm-Based Clustering Protocol for Energy-Efficient Wireless Sensor Networks. IEEE Trans. Ind. Inform. 2013, 10, 774-783. [CrossRef]

26. Demigha, O.; Hidouci, W.-K.; Ahmed, T. On Energy Efficiency in Collaborative Target Tracking in Wireless Sensor Network: A Review. IEEE Commun. Surv. Tutor. 2012, 15, 1210-1222. [CrossRef]

27. Zhou, H.; Liu, B.; Luan, T.H.; Hou, F.; Gui, L.; Li, Y.; Yu, Q.; Shen, X. Chain Cluster: Engineering a Cooperative Content Distribution Framework for Highway Vehicular Communications. IEEE Trans. Intell. Transp. Syst. 2014, 15, 2644-2657. [CrossRef]

28. Xu, Z.; Chen, L.; Chen, C.; Guan, X. Joint Clustering and Routing Design for Reliable and Efficient Data Collection in Large-Scale Wireless Sensor Networks. IEEE Internet Things J. 2015, 3, 520-532. [CrossRef]

29. Heinzelman, W.R.; Chandrakasan, A.; Balakrishnan, H. Energy-efficient communication protocol for wireless micro sensor networks. In Proceedings of the 33rd Annual Hawaii International Conference on System Sciences, Maui, HI, USA, 7 January 2000; p. 8020.

30. Manjeshwar, A.; Agrawal, D. TEEN: A routing protocol for enhanced efficiency in wireless sensor networks. In Proceedings of the 15th International Parallel and Distributed Processing Symposium, San Francisco, CA, USA, 23-27 April 2001; pp. $2009-2015$.

31. Bagci, H.; Yazici, A. An energy aware fuzzy approach to unequal clustering in wireless sensor networks. Appl. Soft Comput. 2013, 13, 1741-1749. [CrossRef]

32. Balakrishnan, B.; Balachandran, S. FLECH: Fuzzy logic based energy efficient clustering hierarchy for non-uniform wireless sensor networks. Wirel. Commun. Mob. Comput. 2017, 1214720. [CrossRef]

33. Baranidharan, B.; Santhi, B. DUCF: Distributed load balancing Unequal Clustering in wireless sensor networks using Fuzzy approach. Appl. Soft Comput. 2016, 40, 495-506. [CrossRef]

34. Phoemphon, S.; So-In, C.; Aimtongkham, P.; Nguyen, T.G. An energy-efficient fuzzy-based scheme for unequal multi hop clustering in wireless sensor networks. J. Ambient. Intell. Hum. Comput. 2021, 12, 873-895. [CrossRef]

35. Boubiche, S.; Boubiche, D.E.; Bilami, A.; Toral-Cruz, H. Big Data Challenges and Data Aggregation Strategies in Wireless Sensor Networks. IEEE Access 2018, 6, 20558-20571. [CrossRef]

36. Dwivedi, A.; Sharma, A. FEECA: Fuzzy based Energy Efficient Clustering Approach in Wireless Sensor Network. ICST Trans. Scalable Inf. Syst. 2018, 7. [CrossRef]

37. Hidoussi, F.; Toral-Cruz, H.; Boubiche, D.E.; Martínez-Peláez, R.; Velarde-Alvarado, P.; Barbosa, R.; Chan, F. PEAL: Power Efficient and Adaptive Latency Hierarchical Routing Protocol for Cluster-Based WSN. Wirel. Pers. Commun. 2017, 96, 4929-4945. [CrossRef]

38. Sert, S.A.; Alchihabi, A.; Yazici, A. A Two-Tier Distributed Fuzzy Logic Based Protocol for Efficient Data Aggregation in Multihop Wireless Sensor Networks. IEEE Trans. Fuzzy Syst. 2018, 26, 3615-3629. [CrossRef]

39. Lee, J.-S.; Teng, C.-L. An Enhanced Hierarchical Clustering Approach for Mobile Sensor Networks Using Fuzzy Inference Systems. IEEE Internet Things J. 2017, 4, 1095-1103. [CrossRef]

40. ElAlami, H.; Najid, A. ECH: An Enhanced Clustering Hierarchy Approach to Maximize Lifetime of Wireless Sensor Networks. IEEE Access 2019, 7, 107142-107153. [CrossRef] 
41. ElAlami, H.; Najid, A. Energy-efficient fuzzy logic cluster head selection in wireless sensor networks. In Proceedings of the 2016 International Conference on Information Technology for Organizations Development (IT4OD), Fez, Morocco, 30 March-1 April 2016; pp. 1-7.

42. Lee, J.-S.; Cheng, W.-L. Fuzzy-Logic-Based Clustering Approach for Wireless Sensor Networks using Energy Predication. IEEE Sens. J. 2012, 12, 2891-2897. [CrossRef]

43. Su, S.; Zhao, S. An optimal clustering mechanism based on Fuzzy-C means for wireless sensor networks. Sustain. Comput. Inform. Syst. 2018, 18, 127-134. [CrossRef]

44. Bruscato, L.T.; Heimfarth, T.; DeFreitas, E.P. Enhancing Time Synchronization Support in Wireless Sensor Networks. Sensors 2017, 17, 2956. [CrossRef] [PubMed]

45. Zhang, D.; Yuan, Y.; Bi, Y. A Design of a Time Synchronization Protocol Based on Dynamic Route and Forwarding Certification. Sensors 2020, 20, 5061. [CrossRef]

46. Wang, Z.; Zeng, P.; Zhou, M.; Li, D.; Wang, J. Cluster-Based Maximum Consensus Time Synchronization for Industrial Wireless Sensor Networks. Sensors 2017, 17, 141. [CrossRef] [PubMed]

\section{Short Biography of Authors}

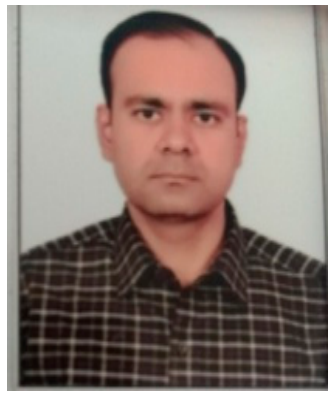

Pankaj Kumar Mishra received his M.E. degree in Computer Science \& Engineearing from Panjab University, Chandigarh and B.Tech. in Computer Science \& Engineering from P.U., Jaunpur, Uttar Pradesh. He is currently an assistant professor at G.B.P.U.A.\&T., Pantnagar, Uttrakhand and Ph.D. student in the Department of Computer Science and Engineering at G.B.P.E.C., Pauri, Uttarakhand. His major research fields are Wireless Networks, Computer Organization, and Cloud Computing.

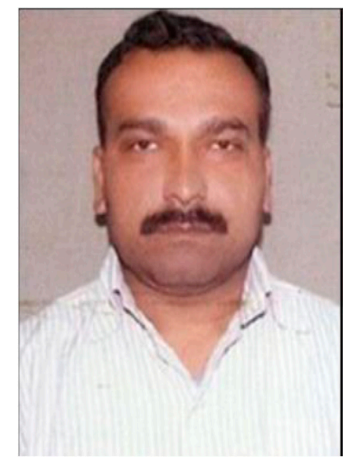

Shashi Kant Verma received the B.E. from G.B.P.E.C, and M.E. from MNNIT Allahabad in 1999 and 2002 respectively, and the Ph.D. degree in 2014. He is now an assistant professor in Department of Computer Science at G.B.P.I.E.T. Ghurdauri. His current research interests are Embedded Systems, WSN, and Signal Processing. 